\title{
Evaluation of Postoperative Bleeding after Thyroid Surgery
}

\author{
Shogo Furukawa ${ }^{1,2}$ Shuji Nishikawa ${ }^{2}$ Masaaki Higashino ${ }^{1}$ Tetsuya Terada ${ }^{1}$ Ryo Kawata ${ }^{1}$
}

\author{
${ }^{1}$ Department of Otolaryngology-Head and Neck Surgery, Osaka \\ Medical and Pharmaceutical University, Osaka, Japan \\ 2 Department of Otolaryngology, Osaka Saiseikai Suita Hospital, \\ Osaka, Japan
}

\begin{abstract}
Address for correspondence Shogo Furukawa, MD, Department of Otolaryngology-Head and Neck Surgery, Osaka Medical and Pharmaceutical University, 2-7 Daigakumachi, Takatsuki, Osaka 5698686, Japan (e-mail: shogo.furukawa@ompu.ac.jp).
\end{abstract}

Int J Pract Otolaryngol 2022;5:e1-e5.

\begin{abstract}
Postoperative bleeding after thyroid surgery is a life-threatening complication. The aim of this study was to identify risk factors for postoperative bleeding. The medical records of 323 consecutive patients who underwent thyroid surgery between 2012 and 2019 at our hospital were reviewed. Bleeding occurred in 11 of the 323 patients (3.4\%). Our analysis revealed no associations of the age, sex, tumor characteristics, or operative factors with the risk of postoperative bleeding. Most patients had symptoms/signs of bleeding, such as cervical swelling, pain/tenderness, and respiratory disturbance. In 5

Keywords

- thyroid surgery

- postoperative bleeding

- complication of the 11 patients who developed postoperative bleeding, the aforementioned symptoms/signs were detected by the attending nurse. Careful observation for up to 24 hours is recommended for early detection of the signs/symptoms of bleeding in patients undergoing thyroid surgery, not only by the surgeon but also by the rest of the care team, including other doctors and nurses attending on the patient.
\end{abstract}

\section{Introduction}

Thyroid surgery is frequently performed in the fields of otolaryngology and head and neck surgery, and many patients undergo thyroid surgery in general as well as specialized hospitals. ${ }^{1}$ Some reports have evaluated postoperative bleeding as a postoperative complication of thyroid surgery, including cases requiring tracheostomy and cases resulting in mortality. ${ }^{2}$ While the mechanism by which postoperative bleeding causes airway obstruction remains largely unclear, ${ }^{3}$ hematoma-induced narrowing of the airway and edema of the larynx are presumably responsible for dyspnea, considering that thyroid surgery involves maneuvers in the vicinity of the trachea. Furthermore, postoperative bleeding must be detected promptly because airway obstruction can be aggravated rapidly. ${ }^{4}$ Therefore, we reviewed cases in which postoperative bleeding occurred after thyroid surgery to identify risk factors, including key signs/symptoms that led to the detection of bleeding.

\section{Patients and Methods}

Informed consent was obtained from all patients and this study was conducted with the approval of the ethics committee of Osaka Medical College. Among 643 patients who underwent thyroid surgery at our department between January 1999 and December 2019 (344 patients with benign tumors or nodules and 299 with malignant tumors), postoperative bleeding occurred in 16 patients (2.5\%). Patients whose surgical wounds needed to be reopened were considered as having postoperative bleeding. Of the 643 cases, 323 in and after 2012 with detailed data were reviewed, and postoperative bleeding was found to have occurred in 11 received

June 9, 2021

accepted

November 5, 2021
DOI https://doi.org/

$10.1055 / \mathrm{s}-0042-1742692$. ISSN 2569-1783.

\footnotetext{
(C) 2022. The Author(s).

This is an open access article published by Thieme under the terms of the Creative Commons Attribution-NonDerivative-NonCommercial-License, permitting copying and reproduction so long as the original work is given appropriate credit. Contents may not be used for commercial purposes, or adapted, remixed, transformed or built upon. (https://creativecommons.org/ licenses/by-nc-nd/4.0/) Georg Thieme Verlag KG, Rüdigerstraße 14, 70469 Stuttgart, Germany
} 
cases (3.4\%). The following data of the 323 patients (11 with postoperative bleeding and 312 without postoperative bleeding) were collected for evaluation: age, sex, body mass index (BMI), maximum tumor diameter, histopathology (benign or malignant), operated side, operation duration, and amount of intraoperative bleeding. For 11 patients with postoperative bleeding, the following data were collected for evaluation: time between completion of surgery and detection of bleeding, signs of postoperative bleeding, the person who detected the bleeding, symptoms/findings, whether the surgical wound was reopened in the ward, laryngeal findings, whether tracheostomy was performed, and the bleeding site. Therefore, changes in the drainage volume over time were also assessed in 11 patients with postoperative bleeding. One and two drains ( $10 \mathrm{Fr}$ ) were placed in patients who underwent hemithyroidectomy and total thyroidectomy, respectively. As a general rule, the drains were removed when the drainage volume reduced to $10 \mathrm{~mL} /$ day or less postoperatively.

For statistical analysis, Fisher's exact test was used for comparisons of sex, benign/malignant tumor, and operated side and Student's $t$-test was used for comparisons of age, BMI, maximum tumor diameter, operation duration, amount of intraoperative bleeding, and drainage volume. The significance level was 0.05 .

\section{Results}

In the 323 patients, comparisons were made between 11 patients with postoperative bleeding and 312 patients without postoperative bleeding. No significant differences between the two groups were found in terms of age, sex, BMI, maximum tumor diameter, and histopathological type. No significant differences between the two groups were also found in terms of operative factors, that is, operated side, operation duration, and amount of intraoperative bleeding

(-Table 1).

The course of postoperative bleeding and changes in drainage volume over time were evaluated in 11 patients

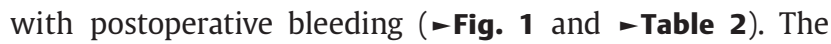
drainage volume increased rapidly in some cases, whereas it increased gradually in other cases, including the two patients who underwent hemostasis more than 24 hours postoperatively. Postoperative bleeding was detected within 6 hours postoperatively in four cases and within approximately 12 hours postoperatively in six cases; these data indicate that postoperative bleeding was found on the day of surgery in $64 \%$ of the cases. The most common symptoms/findings of bleeding included anterior cervical swelling, observed in all the 11 cases; pain (spontaneous pain and tenderness), observed in 7 cases; skin discoloration, observed in 3 cases; and bleeding from the wound, observed in 3 cases. The person who detected the bleeding symptoms/signs was a nurse in six cases, a doctor in two cases, and the patient in three cases. All 11 patients underwent hemostasis under general anesthesia; the bleeding site was identified in nine patients and remained unknown in two patients. Bleeding occurred most commonly from venules at the margin of the anterior cervical muscle (four cases) and less commonly from small blood vessels around the recurrent laryngeal nerve (four cases, including three cases of venous bleeding and one case of arterial bleeding) and as oozing from connective tissue and other sites (two cases). There were no patients in whom bleeding occurred from the anterior jugular vein lying superior to the anterior cervical muscle. Before hemostasis, laryngeal edema was noted in one patient, and no patients had a submucosal hematoma. In addition to hemostasis, tracheostomy was conducted in two patients (-Table 2 ).

The median drainage volume over 10 hours postoperatively in the patients with postoperative bleeding $(45 \mathrm{~mL}$ [19-72 mL]) was significantly larger than that in the patients without postoperative bleeding $(24 \mathrm{~mL} \quad[3-88 \mathrm{~mL}])$ $(p=0.0049)$ (data not shown).

\section{Discussion}

Hematomas associated with postoperative bleeding can cause critical airway obstruction and represent one of the most

Table 1 Comparison of various factors between patients with (11 patients) and without (312 patients) postoperative bleeding

\begin{tabular}{|l|l|l|l|}
\hline & $\begin{array}{l}\text { With postoperative } \\
\text { bleeding (11 patients) }\end{array}$ & $\begin{array}{l}\text { Without postoperative } \\
\text { bleeding (312 patients) }\end{array}$ & $p$-Value \\
\hline Age (y) & $58(18-80)$ & $65(22-91)$ & 0.623 \\
\hline Sex (male:female) & $4: 7$ & $86: 226$ & 0.499 \\
\hline Body mass index & $23.0(16.9-34.9)$ & $22.5(17.6-26.0)$ & 0.248 \\
\hline Maximum tumor diameter (mm) & $23.5(4-102)$ & $25(7-25)$ & 0.590 \\
\hline Benign:malignant & $3: 8$ & $98: 214$ & 1 \\
\hline Operated side (right:left:both) & $8: 3: 0$ & $138: 148: 26$ & 0.132 \\
\hline Operation duration (min) & $104(50-247)$ & $109(50-145)$ & 0.789 \\
\hline Amount of intraoperative bleeding (mL) & $20(5-90)$ & $10(10-45)$ & 0.413 \\
\hline
\end{tabular}

Notes: Student's t-test was used for comparisons of age, body mass index, tumor diameter, operation duration, and amount of intraoperative bleeding.

Fisher's exact test was used for comparisons of sex, benign/malignant tumors, and operated side.

All values are presented as medians. 


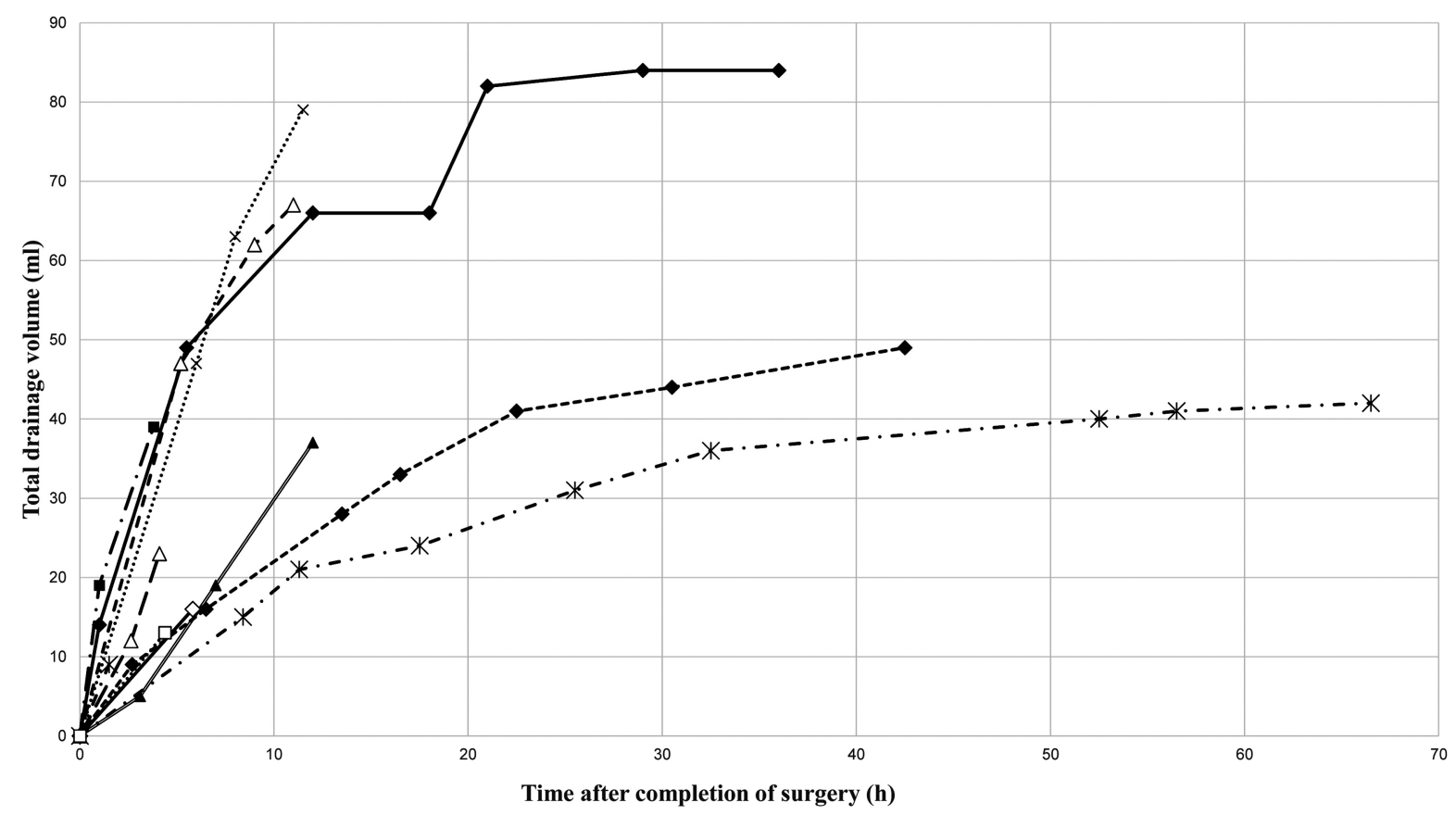

Fig. 1 Changes in the drainage volume over time in 11 patients who developed postoperative bleeding. The drainage volume did not drastically change immediately before postoperative bleeding.

important complications after thyroid surgery. According to a meta-analysis of 25 studies, the incidence of hematomas associated with postoperative bleeding was 6,277 of 424,563 cases (1.5\%). ${ }^{5}$ A study based on the DPC (Diagnosis Procedure Combination) database in Japan reported that 1,123 of 51,967 cases $(2.2 \%)$ of hematomas required tracheostomy/tracheal intubation after surgery or repeat surgery, including 559 cases $(1.1 \%)$ requiring tracheostomy/tracheal intubation only and 564 cases $(1.1 \%)$ requiring surgical removal of hematoma, and the incidence of postoperative bleeding in thyroid-specialized hospitals was $1.3 \%{ }^{2}$ The incidence of postoperative bleeding in this study was $3.4 \%$, which was slightly higher than the reported rate in Japan. The incidence is likely to vary depending on the definition of postoperative bleeding and hematoma; in this study, patients who underwent wound reopening followed by hematoma removal or hemostasis were considered to have developed postoperative bleeding.

In terms of factors associated with postoperative bleeding, Osaku et $\mathrm{al}^{6}$ reported that postoperative bleeding was significantly more common in men, but no significant differences were found for other factors, including age, BMI, surgical procedure, and operation duration. Promberger et $\mathrm{al}^{7}$ also reported that postoperative bleeding was significantly more common in men. While no significant difference between the sexes were found in this study, generally, greater thickness and more developed neck muscle in men may be related to a higher rate of postoperative bleeding.

The respiratory status is not impaired until the severity of airway stenosis attains a certain level, beyond which the respiratory status rapidly deteriorates into suffocation. ${ }^{8}$ The most important measure in case of wound bleeding after thyroid surgery is to avoid the risk of airway stenosis. If postoperative bleeding is severe, the patient has a short neck, or the patient is obese, tracheostomy may be necessary in addition to hemostasis from the perspective of safety management, although there are no clear criteria to determine the necessity of tracheostomy in addition to hemostasis. In this study, tracheostomy was not conducted in four of six cases in which wound reopening in the ward was required. While airway stenosis did not occur, this issue remains to be addressed as a response to airway emergencies associated with postoperative bleeding.

The possible mechanisms underlying airway obstruction owing to postoperative bleeding and hematoma include extratracheal pressure exerted by hematomas, cervical swelling and laryngeal edema because of venous and lymphatic congestion, and resulting recurrent laryngeal nerve paralysis. ${ }^{3}$ These mechanisms are likely to aggravate airway obstruction by interacting with each other intricately; however, a report did not observe direct compression to the trachea. ${ }^{9}$ Given the fact that laryngoscopic findings of hematomas occurring at the wound after thyroid surgery often include swelling and edema mainly in the arytenoid region, a likely mechanism is that hematoma-induced anomalous venous drainage causes edema of the larynx.

While a study mentioned that the wound was opened in the ward after airway obstruction, ${ }^{10}$ at our department, we reopen wounds in the operating room in principle. Wound reopening operations in the operating room have advantages, including the availability of a full lineup of instruments and facilities that ensure successful hematoma removal and hemostasis, more reliable respiratory management, and tracheostomy when needed, in a fully controlled manner. However, dyspnea can be further exacerbated while the patient is moved to the 
Table 2 Eleven patients who developed postoperative bleeding

\begin{tabular}{|c|c|c|c|c|c|c|c|}
\hline $\begin{array}{l}\text { Case } \\
\text { number }\end{array}$ & $\begin{array}{l}\text { Time after } \\
\text { completion } \\
\text { of surgery } \\
\text { (h:min) }\end{array}$ & $\begin{array}{l}\text { Detected } \\
\text { by }\end{array}$ & Symptom or sign & $\begin{array}{l}\text { Wound } \\
\text { reopening } \\
\text { in the } \\
\text { ward }^{\mathrm{a}}\end{array}$ & $\begin{array}{l}\text { Laryngeal } \\
\text { finding } \\
\text { (edema) }^{\mathrm{b}}\end{array}$ & Bleeding site & Tracheostomy ${ }^{c}$ \\
\hline 1 & $2: 36$ & Doctor & Swelling & & - & Multisite oozing & $\times$ \\
\hline 2 & $4: 29$ & Nurse & $\begin{array}{l}\text { Discoloration, swelling, } \\
\text { and spontaneous pain }\end{array}$ & & - & $\begin{array}{l}\text { Venules (site of } \\
\text { penetration of the } \\
\text { recurrent laryngeal } \\
\text { nerve into the larynx) }\end{array}$ & $x$ \\
\hline 3 & $4: 33$ & Nurse & $\begin{array}{l}\text { Bleeding from drain } \\
\text { insertion site and } \\
\text { swelling }\end{array}$ & $\bigcirc$ & - & $\begin{array}{l}\text { Venules (sternohyoid } \\
\text { muscle) }\end{array}$ & $\times$ \\
\hline 4 & $4: 45$ & Nurse & $\begin{array}{l}\text { Discoloration, swelling, } \\
\text { and bleeding from } \\
\text { suture site }\end{array}$ & & + & Unknown & $x$ \\
\hline 5 & $6: 04$ & Doctor & $\begin{array}{l}\text { Swelling, hoarseness, } \\
\text { and spontaneous pain }\end{array}$ & O & - & $\begin{array}{l}\text { Venules (margin of } \\
\text { sternothyroid muscle, } \\
\text { site of penetration of } \\
\text { the right recurrent } \\
\text { laryngeal nerve into the } \\
\text { larynx, and surface of } \\
\text { sternohyoid muscle) }\end{array}$ & $x$ \\
\hline 6 & $10: 42$ & Nurse & $\begin{array}{l}\text { Swelling, discoloration, } \\
\text { and tenderness }\end{array}$ & $\bigcirc$ & - & $\begin{array}{l}\text { Venules } \\
\text { (sternocleidomastoid } \\
\text { muscle, anterior surface } \\
\text { of thyroid cartilage, and } \\
\text { omohyoid muscle) }\end{array}$ & $x$ \\
\hline 7 & $12: 13$ & Nurse & $\begin{array}{l}\text { Swelling and } \\
\text { spontaneous pain }\end{array}$ & $\mathrm{O}$ & - & $\begin{array}{l}\text { Oozing at drain } \\
\text { insertion site and } \\
\text { venules (site of } \\
\text { penetration of the } \\
\text { recurrent laryngeal } \\
\text { nerve into the larynx) }\end{array}$ & $x$ \\
\hline 8 & 19:37 & Nurse & $\begin{array}{l}\text { Swelling and } \\
\text { spontaneous pain }\end{array}$ & $\mathrm{O}$ & - & Unknown & $\bigcirc$ \\
\hline 9 & $42: 39$ & Patient & $\begin{array}{l}\text { Feeling of dyspnea and } \\
\text { swelling }\end{array}$ & $\mathrm{O}$ & - & $\begin{array}{l}\text { Artery lying alongside } \\
\text { the recurrent laryngeal } \\
\text { nerve }\end{array}$ & $\bigcirc$ \\
\hline 10 & $51: 06$ & Patient & $\begin{array}{l}\text { Spontaneous pain, } \\
\text { swelling, and bleeding } \\
\text { from drain insertion site }\end{array}$ & & - & $\begin{array}{l}\text { Venules (surface of } \\
\text { anterior cervical } \\
\text { muscle) }\end{array}$ & $\times$ \\
\hline 11 & $90: 09$ & Patient & $\begin{array}{l}\text { Spontaneous pain and } \\
\text { swelling }\end{array}$ & & - & $\begin{array}{l}\text { Venules (surface of } \\
\text { anterior cervical } \\
\text { muscle) }\end{array}$ & $x$ \\
\hline
\end{tabular}

${ }^{\text {a }}$ The circles indicate that the patient was provided emergency treatment of wounds reopening in the ward.

${ }^{\mathrm{b}}$ The plus symbol indicates that the patient developed laryngeal edema and the minus symbols indicate that they did not develop one.

${ }^{\mathrm{c}}$ The circles indicate that the patient was given a tracheostomy and the multiplication symbols indicate that a tracheostomy was not performed.

operating room. In such cases, the wound is opened before a doctor accompanies the patient to the operating room.

Postoperative bleeding or hematoma is reportedly detected within 6 hours after wound closure in 43 to $80 \%$ of cases and within 24 hours after wound closure in 80 to $97 \%$ of cases. ${ }^{7,11,12}$ In this article, the detection was within 24 hours in 8 of the 11 cases. Wound observation is essential for the early detection of bleeding signs, and it is desirable to observe the wound frequently, particularly within 24 hours after surgery. Cooperation with nurses is essential to detect bleeding signs, such as an increased drainage volume and patients' complaints (e.g., pain). In three cases in which hemostasis was conducted more than 24 hours after surgery, the drainage volume did not increase sharply after 24 hours. In these cases, bleeding is likely to have occurred on the day of surgery rather than more than 24 hours after surgery; after the bleeding was temporarily stopped through hemostatic actions of coagulation and cervical compression, symptoms and signs of hematoma as well as bleeding emerged more than 24 hours after surgery. 
Our ward is specialized in otolaryngology as well as head and neck surgery, and the ward staff members have training sessions for postoperative bleeding after neck surgery, including thyroid surgery. Postoperative bleeding could be detected early in many cases through effective cooperation with nurses, and no patient who underwent cervical surgery at our department has died from postoperative bleeding thus far. The early detection of postoperative bleeding in thyroidspecialized hospitals has been attributed to the involvement of highly trained medical staff. ${ }^{6}$

We place a drainage tube in all patients during thyroid surgery, and the drain is removed the day after the daily drainage volume has decreased to $10 \mathrm{~mL}$ or less after surgery. In patients with uneventful courses after thyroid lobectomy with isthmectomy, the median number of days to drain removal was 4 days (2-9 days). After postoperative bleeding has occurred, the drainage volume can increase sharply or decrease due to obstruction. In this study, no drastic changes in the drainage volume were noted. The drainage volume over 10 hours after surgery in patients with postoperative bleeding was significantly greater than that in patients without postoperative bleeding. Therefore, patients whose drainage volume is large immediately after surgery require careful monitoring; it is desirable to ensure that negative pressure is applied to the drain, particularly within 12 hours after surgery, and to check the drainage volume every 1 to 2 hours if possible. However, caution should be exercised because the drainage volume in patients with postoperative bleeding does not always increase and can substantially decrease when clots block the drain. Attention should be paid to the properties of drainage, in addition to the volume of drainage, because the drainage is expected to become bloody when postoperative bleeding occurs. Besides symptoms and signs listed in -Table 2, findings associated with respiratory disturbance, including respiratory rate, pulse, oxygen saturation, and inspiratory noise, are also useful as observation items for early detection. ${ }^{8,13}$ Additionally, blood pressure must be measured frequently because hypertension has been reported as a risk factor for bleeding. ${ }^{14}$ When swelling cannot be definitely diagnosed as hematoma, it is essential to remove a suture or two without hesitation and confirm the presence or absence of hematoma. Laryngoscopic observation is necessary in cases where hematoma is confirmed and the patient complains of respiratory difficulty. Because all these observations and procedures are difficult to be conducted independently by doctors, team medical care is critically important, and team members should establish a shared awareness of measures against emergencies, such as postoperative bleeding.

\section{Conclusion}

Observation of wounds to check for bleeding signs and patient-reported subjective symptoms as well as monitoring the drainage volume are essential for early detection of postoperative bleeding after thyroid surgery, and medical care by teams of doctors and nurses is important.

\section{Conflict of Interest}

None declared.

\section{References}

1 Fujiwara T, Nonomura M, Haku Y, et al. Can hemithyroidectomy be performed safely by residents? Nippon Jibiinkoka Gakkai Kaiho 2019;122:143-147

2 Suzuki S, Yasunaga H, Matsui H, Fushimi K, Saito Y, Yamasoba T. Factors associated with neck hematoma after thyroidectomy: a retrospective analysis using a Japanese inpatient database. Medicine (Baltimore) 2016;95(07):e2812

3 Koyama H, Kita T, Oe R, et al. Postoperative management of patients after thyroid surgery: important considerations for critical upper airway obstruction. J Jpn Soc Intensive Care Med 2018;25:373-378

4 Kanazawa T, Nishino H. Case-based responses and commentaries: responses to and measures for postoperative bleeding. JOHNS 2018;34:1447-1450

5 Liu J, Sun W, Dong W, et al. Risk factors for post-thyroidectomy haemorrhage: a meta-analysis. Eur J Endocrinol 2017;176(05): 591-602

6 Osaku T, Sugino K, Tanaka T, et al. Risk factors for postoperative bleeding after thyroid and parathyroid surgery. Official Journal of the Japan Association of Endocrine Surgeons and the Japanese Society of Thyroid Surgery 2018;35:200-203

7 Promberger R, Ott J, Kober F, et al. Risk factors for postoperative bleeding after thyroid surgery. Br J Surg 2012;99(03): 373-379

8 Japan Medical Safety Research Organization Medical Safety Information No. 5. Accessed October 16, 2021 at: www.kishoku. gr.jp/common/images/anzen5.pdf

9 Lacoste L, Gineste D, Karayan J, et al. Airway complications in thyroid surgery. Ann Otol Rhinol Laryngol 1993;102(06):441-446

10 Farooq MS, Nouraei R, Kaddour H, Saharay M. Patterns, timing and consequences of post-thyroidectomy haemorrhage. Ann R Coll Surg Engl 2017;99(01):60-62

11 Leyre P, Desurmont T, Lacoste L, et al. Does the risk of compressive hematoma after thyroidectomy authorize 1-day surgery? Langenbecks Arch Surg 2008;393(05):733-737

12 Burkey SH, van Heerden JA, Thompson GB, Grant CS, Schleck CD, Farley DR. Reexploration for symptomatic hematomas after cervical exploration. Surgery 2001;130(06):914-920

13 Agarwal A, Mishra SK. Post-thyroidectomy haemorrhage: an analysis of critical factors in successful management. J Indian Med Assoc 1997;95(07):418-419, 433

14 Morton RP, Vandal AC. Postoperative systolic blood pressure as a risk factor for haematoma following thyroid surgery. Clin Otolaryngol 2015;40(05):462-467 